$11-1994$

\title{
School-Based Management: Promise and Process
}

Priscilla Wohlstetter

Susan Albers Mohrman

Follow this and additional works at: https://repository.upenn.edu/cpre_policybriefs

Part of the Curriculum and Instruction Commons, Educational Administration and Supervision Commons, Educational Leadership Commons, Education Economics Commons, and the Teacher Education and Professional Development Commons

\section{Recommended Citation}

Wohlstetter, Priscilla and Mohrman, Susan Albers. (1994). School-Based Management: Promise and Process. CPRE Policy Briefs.

Retrieved from https://repository.upenn.edu/cpre_policybriefs/52

View on the CPRE website.

This paper is posted at ScholarlyCommons. https://repository.upenn.edu/cpre_policybriefs/52

For more information, please contact repository@pobox.upenn.edu. 


\title{
School-Based Management: Promise and Process
}

\begin{abstract}
This issue of CPRE Finance Briefs summarizes research that investigated how school-based management can be implemented so that it is more than just a catch-phrase. Making the transition to SBM is neither simple nor quick. Neither is it possible for SBM to succeed simply by giving schools more power over such things as budgets, personnel and curriculum. In addition to power, schools need hefty portions of three other commodities that private sector research has found to be essential for making good and productive decisions:
\end{abstract}

Knowledge of the organization so that employees can improve it. Teachers and other stakeholders need technical knowledge, such as how to employ new approaches to teaching, business knowledge, sch as how to develop a budget, and knowledge of interpersonal and problem-solving skills so they can apply what they know to achieving school goals.

Information about student performance and comparisons with other schools about whether parents and community leaders are satisfied with the school, and the resources available, either monetary or other.

and

Rewards to acknowledge the extra effort SBM requires as well as to recognize improvements.

Disciplines

Curriculum and Instruction | Educational Administration and Supervision | Educational Leadership | Education Economics | Teacher Education and Professional Development

\section{Comments}

View on the CPRE website. 




Reporting on issues and research in education finance

\section{School-Based Management: Promise and Process}

by Priscilla Wohlstetter and Susan Albers Mohrman

Whether under the banner of community participation, decentralization or teacher empowerment, schoolbased management has been on the educational reform agenda for decades. Now it is gaining support as a means to improve school performance. But the specific process by which SBM is supposed to lead to performance improvement has received little attention and efforts to achieve that goal have been hit-andmiss.

So far, there is scant evidence that schools get better just because decisions are made by those closer to the classroom. That deceptively simple change in how schools are managed and governed, as attractive as it is to many teachers, principals and parents, turns out to be rather meaningless unless it is part of a focused, even passionate, quest for improvement. School-based decision-making is one aspect of systemic school reform-an approach to improving schools that also includes changing instruction, curriculum, the institutional web that surrounds schools to achieve an integrated focus on the outcomes of education.

In fact, the absence of a clearly defined set of instructional goals tends to slow the progress of even the governance changes SBM is supposed to deliver. The changes tend to occur on paper only, without engaging the support or enthusiasm of those who must carry them out. This also has been seen in the private sector, which has increasingly adopted the tenets of decentralized decision-making to invigorate production or improve service delivery. When decentralized management was thought of solely as a way to help employees feel better about their jobs, it gained little support from managers or workers. But when employees and managers were asked to rethink their relationships and their involvement to achieve certain business-related goals, such as improving quality or raising productivity, organizational change was far more likely.

The bottom line is that school-based management is not an end in itself, although research indicates that it can help foster an improved school culture and higherquality decisions. School-based management is, however, a potentially valuable tool for engaging the talents and enthusiasm of far more of a school's stakeholders than traditional, top-down governance sytems. Moreover, once in place, SBM holds the promise of enabling schools to better address students' needs. This promise is more likely, however, if a "highinvolvement" model of SBM is followed. This model envisions teachers and principals being trained and empowered to make decisions related to management and performance; having access to information to inform such decisions; and being rewarded for their accomplishments.

Priscilla Wohlstetter is associate professor of politics and policy in the School of Education at the University of Southern California where she directs the School-Based Management Project for the Finance Center of the Consortium for Policy Research in Education. Susan Albers Mohrman is deputy director of the School-Based Management Project and senior research scientist with the Center for Effective Organizations in the School of Business at the University of Southern California. The School-Based Management Project has received generous support from the Office of Educational Research and Improvement, U. S. Department of Education and from the Carnegie Corporation of New York. 
This issue of CPRE Finance Briefs summarizes research that investigated how school-based management can be implemented so that it is more than just a catch-phrase. Making the transition to SBM is neither simple nor quick. Neither is it possible for SBM to succeed simply by giving schools more power over such things as budgets, personnel and curriculum. In addition to power, schools need hefty portions of three other commodities that private sector research has found to be essential for making good and productive decisions:

Knowledge of the organization so that employees can improve it. Teachers and other stakeholders need technical knowledge, such as how to employ new approaches to teaching, business knowledge, such as how to develop a budget, and knowledge of interpersonal and problem-solving skills so they can apply what they know to achieving school goals.

Information about student performance and comparisons with other schools, about whether parents and community leaders are satisfied with the school, and about the resources available, either monetary or other.

Rewards to acknowledge the extra effort SBM requires as well as to recognize improvements.

Our conclusions about SBM are based on an in-depth study of 27 schools in three U. S. districts (Jefferson County, Kentucky; Prince William County, Virginia; and San Diego, California), one Canadian district (Edmonton, Canada), and one Australian state (Victoria) that have been operating under the SBM umbrella for about four years, although some have been working at it much longer. We interviewed nearly 200 individuals from school board members, superintendents and associate superintendents in district offices to principals, teachers, parents and students in local schools.

Slightly more than half the schools studied could be characterized as "actively restructuring," meaning that reform efforts had successfully produced changes in curriculum and instructional practices. The other half were struggling, meaning that they were going through the motions of SBM but little change had occurred. The two categories of schools differed on each of the four previously mentioned dimensions. These differences offer guidance for tapping the potential of SBM.

\section{Power}

Questions of power-how much is transferred to the school and who wields it-are among the central SBM policy issues. Most SBM schools establish a site council but the composition, role and leadership of councils vary. Some school districts dictate that structure, as in San Diego; others leave it up to the schools themselves, but hold the principal accountable for ensuring that all parties are given the opportunity to contribute, such as in Prince William County. In Jefferson County, schools had leeway within a set of guidelines generated collaboratively by the district and the teacher association.

Interestingly, councils established by the schools themselves and those structured by district order differed little. Most had administrative, teacher, parent and classified employee representatives, who were elected by their respective constituencies. Edmonton schools did not require site coun- cils. Instead, principals devised their own, often informal, ways of seeking teacher input. The parents' perspective was usually solicited through separate parent advisory councils.

Most of the actively restructuring schools had some means of dispersing power, usually through subcommittees. The subcommittees not only engaged more of the faculty, either as members or leaders, but also they reduced the work load on individual teachers and broadened the commitment to reform. Parents often were active members of subcommittees, too, although leadership positions were held usually by educators. Parents were most concerned about issues related to the school environment (e.g., safety, uniforms) and tended to view areas like curriculum and instruction and staff development as professional issues to be handled by educators.

In Australia, subcommittees had control over a small budget, which helped facilitate the implementation of reform efforts. The subcommittees, set up to address such topics as curriculum, assessment and professional development, also helped focus participants' energy on specific tasks rather than on abstractions such as "culture" or "empowerment." The net effect was that in actively restructuring schools there was lots of communication and reflective dialogue around specific projects.

The struggling schools got bogged down in establishing power relationships. They tended to concentrate power in one faculty group, leading to an atmosphere of "us" and "them." One struggling school spent almost a year developing a policy manual that specified who had power and under what conditions. Other research also has found that at 


\section{Characteristics of Actively Restructuring Schools}

1. Schools saw themselves as engaged in a broad set of reform activities, not simply implementing SBM as an end in itself.

2. Schools had clearly written vision statements that often were developed collectively by school staff under the guidance of the principal. Thus, there was schoolwide consensus about where the school was going and the principal assisted in helping it get there.

3. Schools created multiple, teacher-led decision-making teams that cut across the school both horizontally and vertically to involve all teachers in the decision-making process. The teams also fostered high levels of information sharing and interaction around issues related to school performance.

4. Schools learned new ways to involve parents in the school community, and worked actively to be responsive to parents' concerns and to keep them informed.

5. Schools used state and district curriculum frameworks to focus reform efforts and to target changes in curriculum and instruction. The instructional guidance mechanisms also helped to set the work agendas of the various decision-making teams.

6. Schools redesigned their schedules to encourage teacher interaction during the regular school day. Thus, teachers at the same grade level, in the same subject area or on the same decision-making team used common planning periods, for instance, to work together on specific tasks.

7. Principals were more facilitators and managers of change than instructional leaders. Teachers often took the lead in the areas of curriculum and instruction.

8. Schools made heavy investments in professional development to expand both the organizational and individual capacity of the school. Such activities focused on the development of team process skills, as well as instructional staff development.

9. Schools were assisted in their restructuring efforts by district offices that encouraged risk-taking, and that offered technical assistance and support in response to school requests.

10. Principals took care to recognize the efforts of school staff through thank-you notes, and public acknowledgments in newsletters or at faculty meetings.

schools dominated by adversarial politics, council discussions more often were related to power conflicts rather than to instructional issues.

Making good use of the power accorded schools under SBM also depends on superintendents and principals. Superintendents helped by making central offices serviceoriented: "The schools want helpers, not tellers." In Edmonton, schools had the bulk of money for professional development and maintenance, and could purchase those services outside the district. Central office depart- ments offering such services became school-oriented as they had to sell their services to schools in order to stay in existence.

District office restructuring and total quality management efforts in San Diego and Prince William County promoted the notion of the schools as the customers of the district departments. Superintendents also worked to develop a districtwide culture of risk-taking. The superintendent in Jefferson County encouraged schools "to go out on a limb" and supported them by offering extra money for professional development to all schools that voted to adopt SBM.

It is clear from actively restructuring schools that SBM does not mean that principals no longer have a role to play. Rather, they play a different role. We saw evidence in some schools that principals were moving away from being the instructional leader, while in others the principal concentrated on conveying a strong instructional vision. In all restructuring schools, principals were moving toward the role of facilitator and manager of change.

Principals at actively restructuring schools worked to broaden and sustain the school's commitment to reform by getting various stakeholders involved in decisionmaking teams. Principals in those schools motivated staff, created a team feeling on campus, and often provided a vision for the school. Successful principals also shielded teachers from issues in which they had little interest or expertise so that they could concentrate on teaching.

Principals in struggling schools were at odds with their staff and were accused of failing to support them or, in the extreme, of vetoing or ignoring site council 
decisions. Teachers at those schools often were not willing to accept guidance and leadership from the principal or else they feared too much interference from the parent participants. Furthermore, principals in these schools often loaded up the council with trivial issues.

\section{Knowledge}

Districts considering a move to SBM should be aware that the demand for professional development will increase. Not only do school-site educators need ongoing assistance with content and pedagogy, but also with skills such as group problem-solving, conflict resolution and time management. Principals need help understanding in enacting their new roles.

Our research also pointed out the need to train other SBM participants at the school site, such as parents, administrators and students, who serve on the various decision-making teams. Further, we found a critical need to retrain central office administrators who are more accustomed to being enforcers, regulators and overseers than to responding to requests from schools for technical assistance.

Two of the districts we studied created new organizational arrangements at the associate superintendent level to supply support services to schools-Edmonton's Staff Development Office and Jefferson County's Gheens Academy. Consultants were available for customized campus training and teachers frequently traveled to the district office for development activities, which were offered after school hours and on weekends to encourage teacher participation. At the other extreme were Prince William
County and San Diego where both superintendents reported that they had initially greatly under-estimated the amount of training and development that would be required to support SBM.

Those working in "actively restructuring" schools were intensely interested in professional development, which was viewed as an ongoing formal process for teachers as well as the principal. The goal was to develop a schoolwide capacity for organizational and individual improvement.

Development activities were designed to promote a sense of professional community and a shared knowledge base among the faculty. Topics for professional development at these schools usually were decided on by the faculty and principal, so the topics were tailored to the school's particular needs. In addition, the actively restructuring schools sought out a variety of resources in the community, including private companies and universities, to provide for their training and development needs and did not rely solely on the district office.

Professional development at the struggling schools tended to be, by and large, an individual activity rather than a means of creating a schoolwide capacity for improvement. Fewer staff participated in development activities and they tended to be offered only sporadically. The format usually was of the "go, sit and get" variety and the subject matter of development activities often was controlled by the central administration. Moreover, the topics at these schools were more likely to be narrowly focused and even outof-touch with the day-to-day issues faced by teachers.

\section{Information}

Effective management requires useful information about the progress an organization is making toward meeting its goals, and about how customers are perceiving its services. All of the schools we studied had mechanisms such as newsletters or parent-teacher conferences for communicating with parents about school performance. In addition, some school districts made available information schools could use to compare themselves to others. Information was also shared in principal-to-principal meetings, district conferences and computer networks, although these seemed to be used less frequently.

The actively restructuring schools used decision-making teams that cut across the organization both vertically and horizontally for communicating and sharing different kinds of information with various stakeholders. Consequently, the schools that dispersed power throughout the organization also tended to be the ones with the most informed school-site participants.

In Victoria, the state developed an on-line interactive computer system that included revenue, expenditure and budget information; data on student achievement; electronic invoicing and purchasing; and a student schedule. This computer network was by far the most advanced among the districts we studied, although several other districts, including Edmonton and Jefferson County, have linked school sites electronically with the district office.

Restructuring schools also had a strong customer service orientation. In Edmonton, for example, the district has for more than a decade conducted yearly satisfaction surveys of students and staff. 
In alternate years, the district also surveys parents and the general public to assess their satisfaction with the public schools. Survey results are released each fall and campuses typically use the information to target improvements.

Struggling schools, in contrast, tended to have fewer formal mechanisms for sharing information, and the flow of information was often top-down, as in traditional schools. As a result, the teacher grapevine was usually the primary means of communication and unfortunately, the information on the grapevine was often incomplete and tended to breed suspicion.

Across all SBM districts that we studied, the districts had little capacity for gathering information in a form useful to individual schools. Traditionally, corporations and schools have gathered aggregate information most useful for making decisions in a central office.
Schools engaged in SBM need distributed information to make good decisions. SBM districts generally were able, albeit often not in a timely manner, to collect and circulate financial information to support decisions related to budgets and resource tradeoffs. They were less able to collect information about the performance of the school organization, such as tracking staff development activities and assessing the progress of innovations.

\section{Rewards}

Rewarding effort is as problematic in SBM schools as in others. Many schools recognized efforts with thank-you notes, mentions in school newsletters and other acknowledgments. But several principals said they preferred to de-emphasize the idea of winners and losers in order to create a sense of community achievement. Some schools scheduled year-end functions, with free dinners,

\section{The Change Process in SBM Schools}

- Decentralizing authority or power to schools will not automatically lead to the effective utilization of that power. Authority must be accompanied by a principal who facilitates participation, a school faculty with few divisive factions, and a general desire of stakeholders to be involved with reform.

- Schools take time to learn how to function with SBM. In the beginning, decision-making may focus on issues that are more trivial in nature, such as access to the copying machine, before moving to more complex issues, such as curriculum and instructional practices.

$\rightarrow$ School culture is critical to the change process. Schools achieving instructional change created cultures characterized by an atmosphere of collaboration and trust among staff and a focus on continuous improvement. Greater levels of participation by staff and parents, as well as structures that include all stakeholders in the decision-making process can facilitate improvements in school culture.

- As part of the school change process, individual behavior may also change. Behavior changes include talking about and observing teaching practices, maintaining higher standards of performance, seeking out new ideas, and actively becoming involved in schoolwide issues. flowers and parties, to celebrate the achievement of school goals.

Few financial rewards were used in SBM schools and when they were, rewards like the other types of acknowledgments were usually given to groups and often schoolwide. Some schools gave teachers who wrote grants a reduced course load or stipends for attending staff development activities on weekends or during the summer.

In Edmonton and Prince William County, schools were rewarded for being frugal; cost savings were carried over from one year to the next and placed in a discretionary pot to be used as the school wanted. In Kentucky, the state has responsibility for meting out sanctions and rewards to local schools and we saw evidence that these were providing an impetus for change in many schools and on teachers' minds as they went about improving classroom practice.

Across all SBM schools we studied, most teachers said they still relied on intrinsic satisfactions for motivation. But at actively restructuring schools that intrinsic, or psychic, satisfaction seemed more readily available than at others.

The lack of reward structures could be an impediment to the success of SBM. Participants at some point may not be able to maintain the same high level effort without being rewarded for that effort. Teacher burn-out that some schools have experienced with SBM may be evidence of this.

In the private sector, rewards can be allocated directly, for achieving certain skills or meeting organizational performance targets. In education, however, rewards so far are, at best, indirect and un- 


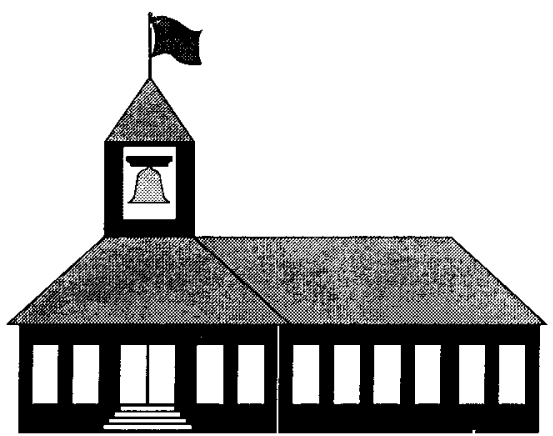

focused. Years of teaching experience and degrees are rewarded rather than progress made toward SBM goals or improvements in student achievement.

\section{Implementing School- Based Management}

The transition to school-based management is a large-scale change. It is intended to fundamentally change the capacity of the school by increasing the involvement of school-level stakeholders in managing the school and improving its performance. When successful, the transition is both pervasive and deep. It is pervasive because it requires change in almost all aspects of the organization: structures, roles, systems, instructional practices, human resource practices, and the skills and knowledge of participants. It entails change in schools and in the district offices.

Implementing such change is not a straightforward adoption process. Rather, it is a gradual iterative process of introducing and refining changes until all aspects of the organization support this new way of functioning.

Our successful schools had been at it for several years, and were learning and gradually putting in place the elements of effective school-based management and educational improvement. Likewise, the districts we studied were gradually introducing changes in the information, accountability and control systems to enable schools to be self-improving entities and to be able to more effectively manage themselves, as well as changes to the districtlevel organization to support and stimulate school-level improvement.

The transition to school-based management is deep change, because it entails fundamental change in people's understanding of the organization and their role in it. The schools that had introduced new approaches to instruction were those where the community of teachers learned new ways of teaching, and expanded their view of their role in the organization beyond the confines of their classroom. Principals learned new ways of influencing and leading, and began to see themselves as managers of change.

Principals in the restructuring schools in Prince William County, for example, had received change management training. They described the change dynamics in their schools, and their plans for helping the school move through the stages of change. Actively restructuring schools learned new ways to involve parents and created new relationships to community organizations. The stakeholders developed a shared understanding of what the school was trying to accomplish and how. School personnel developed a realization that they would have to be effective in meeting the needs of their clientele and their communities, and that to do so would require introducing new approaches.

The introduction of instructional change was not an automatic consequence of establishing schoolbased management. Successful schools laid the foundation for change. They jointly determined their values: their vision of success and the outcomes they were after. Several schools in Jefferson County held an annual Fall retreat offsite to begin the year with a review of programs and planning to achieve its vision.

Successful schools also took time to educate themselves regarding different approaches to achieving valued outcomes, through visiting and exposing themselves to different organizations, and considering learnings from both school and private sector organizations.

One Prince William County school wrote a grant proposal and received one year of funding to support visits and staff development activities designed to create a collective sense of purpose and approach to dealing with the changing school population. They developed a collective sense of the need for change, by defining the gap between where they were and where they needed to be to meet the needs of their students. Subsequent grants were solicited for defining and implementing a new educational philosophy.

Often the district played an active role in helping lay the foundation, by providing an overarching set of goals, helping articulate state frameworks, and providing educational and developmental experiences. Even when the district provided strong change leadership, local school activities were required to develop a shared understanding and collective energy. Where deep divisions remained within faculties or between teachers and administrators, schools did not move to the next step of planning and implementing change. Such divisions were particularly problematic in the struggling secondary schools in our study. 
School-based management has profound implications for how and where decisions are made; however, effective decisionmaking is not an automatic consequence of decentralizing decisions to the school. Schools that were successful introducing changes in instructional practice had developed effective decisionmaking processes. Decisionmaking was not confined to a narrow group of people who composed the council. Staff, parents, and sometimes students gave input and got involved.

Three types of barriers to effective decision-making were observed: (1) principals who were autocratic or who failed to utilize input; (2) staff factionalism, including competition between departments or divisiveness between those in favor of reform and those opposed; and (3) staff apathy and unwillingness to get involved.

One element of effective schoollevel decision making was the existence of multiple decisionmaking teams and a clear sense of how they related to one another. In many cases, the constellation of teams changed over time as the school developed a sense of what decision-making forums were needed, such as in Victoria where successful schools typically had grade-level and school-wide teams with overlapping memberships.

Other elements present in the schools with effective decisionmaking were: the training of all participants in team skills and decision-making skills; joint diagnoses of the problems teams were working on; allowing teams to make decisions with no principal override; providing teams with good information upon which to make data-based decisions; and finding ways to broaden the perspectives of participants through such approaches as visiting and seeing effective practices at other schools.

Leaders played important roles in the implementation of SBM and the application of school efforts toward the accomplishment of school improvements. The principals in the successful schools were generally seen as effective leaders, but there were generally strong teacher leaders as well. Principals often were active in managing the change process, including a participative process for determining a shared vision, and communication and support for that vision at every opportunity. Much of the hands-on work of designing and implementing change was delegated to participants throughout the school. Teachers typically served as chairs of subcommittees and became recognized experts by their colleagues in specific arenas (e.g., curriculum design, student assessment, use of technology).
Many of the schools that were the most successful in introducing change were also the most proactive and successful in obtaining resources. They wrote grants, solicited community partnerships, took advantage of district and regional services, and generally sought out opportunities to obtain expanded resources.

Teachers in these schools invested large amounts of time planning and learning about new approaches, and the successful schools did not sit and wait for the district to provide extra resources to support this. They were entrepreneurial. These schools found ways to create time and resources for needed staff development and common planning activities. One school in Jefferson County arranged schedules so that all students in a specific grade had resource activities-library, physical education, music-at the same

This brief is based on the following publications prepared for the School-Based Management Project being conducted by the Finance Center of CPRE. These works report on findings from three years of studying site-based management in school districts and states in the United States, Canada and Australia.

Mohrman, S. A. \& Wohlstetter, P. (1993, October). "School-Based Management and School Reform: Comparison to Private Sector Renewal."Working Paper. Los Angeles: University of Southern California, The School-Based Management Project.

Mohrman, S. A. \& Wohlstetter, P. (1994). School-Based Management: Organizing for High Performance. San Francisco: Jossey-Bass.

Odden, A. \& Odden, E. (April, 1994). “Applying the High Involvement Framework to Local Management of Schools in Victoria, Australia." Working Paper. Los Angeles: University of Southern California, The School-Based Management Project.

Robertson, P. J. \& Briggs, K. L. (1993, October). "Managing Change Through School-Based Management." Working Paper. Los Angeles: University of Southern California, The School-Based Management Project.

Wohlstetter, P., Smyer, R., \& Mohrman, S. A. (1994). "New Boundaries for School-Based Management: The High Involvement Model." Educational Evaluation and Policy Analysis, 16(3), 268286. 
time. This freed up time each week for the classroom teachers to meet together to plan activities.

It is clear that school improvement is a process. It is also clear that process takes time, and is not easily predictable. School decisions have to improve and new practices have to be put in place and behaviors altered before students begin learning more. Implementing effective schoolbased management involves establishing effective decision-making forums and designing the organization to make it possible and likely for these to generate and implement new and more effective approaches to teaching and learning. It involves new information systems, increased skills and knowledge development, and aligning rewards and motivation with the new performances that are required.

This complex change process needs to be monitored and assessed, so that the organization can discover where its implementation has fallen short, and its approaches need to be modified. In each of the districts we studied school, community, district and association leaders were on the learning curve, gradually discovering what is required for SBM to work effectively and to contribute to improvement in teaching and learning. Among schools, there were huge discrepancies in the extent to which the school level participants were learning to be more effective. Actively restructuring schools were actively learning how to become more effective in achieving their focused educational goals.

\section{The Consortium for Policy Research in Education}

CPRE Finance Briefs are published occasionally by the Consortium for Policy Research in Education. The Consortium operates two separate, but interconnected research centers: The Finance Center and The Policy Center. CPRE is funded by the U. S. Department of Education's Office of Educational Research. The Policy Center of CPRE is supported by grant \#OERI-R117G1007; the Finance Center of CPRE is supported by grant \#OERI-R117G10039.

For further information on CPRE publications contact Pat Michaels, publications assistant, at CPRE, Carriage House at the Eagleton Institute of Politics, Rutgers University, 86 Clifton Avenue, New Brunswick, NJ 08901$1568 ; 908 / 932-1331$.

The views expressed in CPRE publications are those of individual authors and are not necessarily shared by the Consortium, its institutional members, or the U. S. Department of Education. 